\title{
Coordinating the Service Process of Two Business Units towards a Joint Customer
}

\author{
Rita Lavikka, Riitta Smeds, Miia Jaatinen and Emmi Valkeapää \\ SimLab, Department of Computer Science and Engineering, Helsinki \\ University of Technology (TKK), P.O. Box 9220, FIN-02015 TKK, Finland \\ http://www.simlab.tkk.fi/contact.htm \\ Tel. +358 50384 1662, Fax +358(0)9 451 4698, rita.lavikka@tkk.fi
}

\begin{abstract}
The paper presents a new theoretical framework for coordinating an inter-unit collaborative service process towards a joint customer. The common service process is itself presented as a central coordination mechanism. It defines how tasks and responsibilities are shared between the collaborating units. The framework presents the factors supporting cooperation between the units, the prerequisites of the common service process, and the ways of coordination suitable for inter-unit cooperation. The framework is developed through a single-company longitudinal, qualitative case study that consists of three action research projects.
\end{abstract}

\section{Keywords}

Coordination, collaboration, service process, case study, action research

\section{Introduction}

Cooperation between organizations is necessary in the fast developing business world to add value for the end-customer. In practice, added value can be produced by broadening the service offering. According to Grönroos [1], it is a challenge to provide a joint service offering and it requires cooperation between the service providers. Cooperation between companies, but also between business units inside one company, must be supported and coordinated. Thus, a study on how collective human activity should be organized is required [2].

The objective of our research was to study how cooperation between business units of a single company can be supported and coordinated. As the main result of this research we present a new framework for coordinating a collaborative service process to produce better service offering to the joint customer. 
The framework was developed in a case study in which cooperation between two business units inside one company was improved and the service processes of the units were integrated and coordinated. The need for coordination arose as the units realized that they needed to serve the common customers better by enlarging the product and service offering, but the units were too decentralized to do this together. The business units also tried to improve their competitive advantage by finding synergies through collaboration. [3]

\section{Theoretical Background}

\subsection{Coordination of Interdependencies}

Different units of organizations are usually specialized in certain operations, which differentiates the units from each other. However, the interdependencies between the units need to be managed to produce high-quality products and services together. Thus, coordination, i.e., the integration of different parts of the organization is needed in order to achieve common objectives [4].

The difficulty lies in determining how to coordinate different interdependencies between business units. Hall [5] claims that there is no one way to coordinate, but the suitable coordination mechanisms depend on the environment.

Thompson [6] presents three types of task interdependencies (pooled coupling, sequential coupling, and reciprocal coupling) and three modes of coordination (standardization, planning, and mutual adjustment) to manage these interdependencies. Mintzberg [7] continues Thompson's work in the field of coordination by stating that a fourth mode of coordination, i.e., direct supervision exists. Mintzberg's modes of coordination are intended for different organizational structures.

We combined Thompson's [6] and Mintzberg's [7] work on coordination. Thus, we present four modes of coordination suitable for different kinds of environments: planning, mutual adjustment, direct supervision, and the standardization of work processes, output, or skills needed to accomplish the work. Planning is suitable in dynamic situations where tasks are changing frequently. Mutual adjustment suits in dynamic environments when tasks are interrelated. Direct supervision is suited for a small organization where task interdependencies change. Standardization is suitable for environments that are mainly stable and the work activities are interrelated. $[6,7]$

\subsection{Supporting Cooperation and Improving Service Quality}

Hoeg [8] and Simatupang et al. [9] state that cooperation between organizations needs to be improved in order to together form a product that satisfies customers. Axelsson and Easton [10] present that organizations should be integrated (i.e., become a whole) before the coordination of their operations can be started.

We hypothesize that factors supporting cooperation provide organizations with integration mechanisms. We present five factors supporting cooperation: common will and values [11], common understanding [12,13], common development projects [11], internal customership [14], and communication [15]. We chose these factors 
because they suited well in the context of our case study, i.e., two business units trying to cooperate inside one company.

Service quality depends on the quality of both the service process and its endresult. Service process can be defined as a chain of sequential and/or parallel activities that have to work in order to produce a service. [16] According to Grönroos [1], a service process involves both the production and delivery of services. The relationships between quality generating resources (personnel, service idea, systems, and customers) have to be coordinated in order to improve service quality [1].

\section{Methodology}

This study applies abductive reasoning $[17,18]$. First, a preliminary theoretical framework was developed based on theory. Then, the framework was tested using deductive reasoning in empirical research. The findings from the empirical research were generalized inductively to theory as a new framework. The empirical part is based on a qualitative case study $[19,20]$ in which action research was carried out [21].

The case study of this paper is focused on cooperation between two business units of a Finnish media company. The data was collected during three developmental action research projects following the SimLab ${ }^{\text {TM }}$ method. During SimLab action research project, researchers prepare and implement a process simulation together with case companies. This includes setting goals, interviewing relevant parties, modeling the selected business processes, organizing a simulation day, analyzing results, and giving feedback. [22, 23] The simulation day includes a facilitated group discussion in front of a visual process model and group work sessions for developing further the solutions. The first and third writer of this paper acted as facilitators in the first action research project, whereas the first and fourth writer acted as facilitators in the second and third action research projects.

Each of the three consecutive projects lasted around three months. The data was gathered between October 2004 and November 2005. The qualitative data in the preparation and running of the three action research projects included altogether 40 semi-structured interviews, observation, and three questionnaires. Additional sources of information included documents provided by the business units or created during the action research project, such as process charts and management presentations on the case company's business models and objectives.

The semi-structured interviews of this study concentrated on predetermined topics selected by the researchers, but the flow of discussion was free, hence, relevant topics emerging during the interviews could be talked through [24]. The topics of the interviews were related to developing and coordinating the cooperation between the business units. The interviews were digitally recorded and then transcribed into text files word for word. After that, they were analyzed by marking the relevant pieces of the text and classified into themes (i.e., content analyzed).

The observation in the study was holistic in nature [25]. We made observations on the behavior of the participants during the projects and later talked through these observations with other researchers. The participants of the interviews, simulation 
days, and questionnaires included employees from the management level as well as from the operational level. Three common customers of the units were interviewed and altogether 21 common customers participated in the first and second simulation days.

Three questionnaires were designed to ask the respondents' opinions about ways to manage cooperation and the ways of coordination. The questionnaires were handed to the participants of the simulation immediately after each simulation day. There were open-ended questions and rating questions. The questionnaires were anonymous in order to elicit honest opinions. The answers to the open-ended questions were classified into themes, and the answers to the rating questions were average calculated. In the first project all 27 participants answered. In the second project 21 out of a total of 26 participants answered. In the third project 35 out of a total of 37 participants answered. Some of the respondents participated in all three projects and answered three times.

\section{Case Description}

The case study involved two business units (product and service unit) within a Finnish, international company operating in media industry. The units served partially the same customers. The product unit provided traditional physical products, whereas the service unit provided an Internet-based service. Both units had their own customers as well as common customers. The units had separate business models. In the beginning of the study, the personnel regarded these two issues as inhibiting factors to cooperating more intensively and gaining synergy.

The traditional product unit employed over 100 people. It generated ten times the profit of the other unit. The different operations of the product unit were coordinated by regular meetings, email, and daily ad hoc communication, such as phone calls and face-to-face discussions. The service unit was quite small, employing only 13 people. The service unit did not yet generate much profit as it was recently founded as a development unit. The employees of the service unit worked near each other. Hence, the ways of coordination included mainly informal and ad hoc communication.

The three consecutive action research projects had a common purpose to improve cooperation between the two units in order to serve the common customers better and to find synergies. This was achieved by coordinating the work of selected collaborating operations of the units. In addition, each development project had its own specific goals.

The goal of the first action research project was to build a common frame of cooperation between the business units in order to give the customers a consistent image of the products and services of the units. This challenge required improving communication between the units. The 21 participants of the action research project represented mainly the customer service operations of both units. In addition, 20 common customers participated in the simulation day. In the end of the first action research project, the units realized that the modeling of a common service process could be used as a cooperation process to coordinate the operations of the units. 
In consequence, the goal of the second project was to model a common service process that would integrate the marketing and customer service operations of the units. The project also aimed at supporting the formation of common will between the two units. The common will meant that the units could agree on what the units want to be together in the future and how to get there. The project included $27 \mathrm{em}$ ployees altogether from the customer service and the marketing operations of the units.

In the third action research project, the common service process was extended to cover also the electronic sales and distribution operations of the business units. There was a need to understand the potential advantages of common product and customer relationship management systems. Other goals were improving communication and common understanding between the units as well as finding ways to integrate the electronic sales and distribution operations of the units. Altogether 37 employees participated in the action research project. They came from the electronic sales and distribution operation, customer service operation, and marketing operations.

\section{Results}

The developed framework for coordinating a collaborative service process is presented in the Fig. 1. The framework contains three zones: the factors supporting cooperation, the prerequisites of common service process, and the operations of common service process and their ways of coordination.

Based on empirical findings, we recognized seven factors that were considered to support cooperation (Outer zone in the Fig. 1): a common profit goal, common understanding about the units' business, common will and values, a common strategic plan, common process simulation projects, internal customership, and communication. Some of the factors were modified from theory (see chapter 2.2).

The results of the case study show that in order to have better service, the separate business units can coordinate their operations by first modeling a common service process together, and then by acting according to it. The common process model defines, e.g., how operations between collaborators' organizations should be coordinated and managed. In addition, the model can define prescheduled planning meetings where coordination challenges related to common business are discussed and solved. Thus, we present that a common service process between organizations can act as a coordination method.

Based on empirical study, the prerequisites of a common service process (Middle zone in the Fig. 1) are a shared service idea, shared knowledge about the products and services, common understanding about the customers' needs, and shared product and customer relationship management systems. These four elements which were modified from theory [1] tie together the operations of two business units.

In the case study, we categorized the operations of the units into three categories: Marketing, Electronic sales and distribution, and Customer service. The researchers recognized ways of coordination (Inner zone in the Fig. 1) that were specifically used inside these operations. Two ways of coordination were used in all of these op- 
erations. These were common ways of operating and external integrators. The framework also presents other ways of coordination. (Fig. 1)

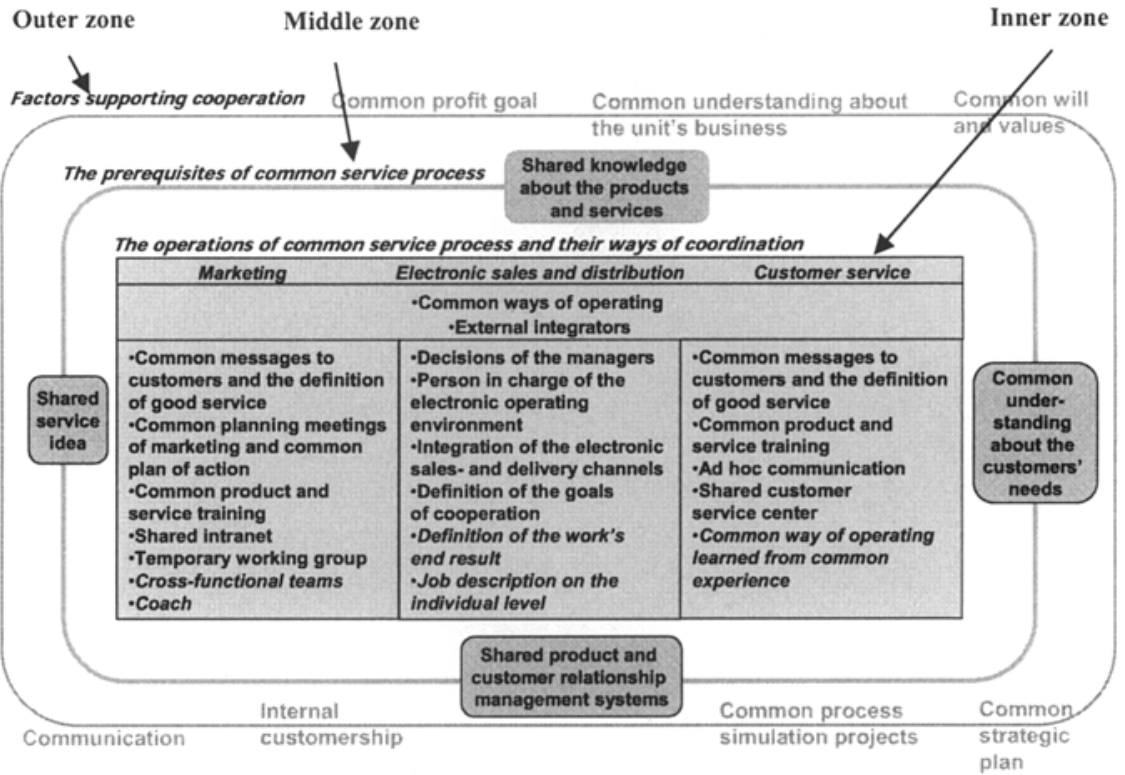

Fig. 1. The framework for coordinating a collaborative service process for better service [3]

The study suggests that a common strategic plan and a common strategic profit goal can be regarded as development and coordination methods on the organization's strategic level. They correspond to Mintzberg's [7] standardization of output.

In addition, the study suggests that the common ways of operating in customer service, common messages to customers, the definition of good service, and ad hoc communication can be regarded as development and coordination methods on the organization's operational level. The common ways of operating in customer service correspond to Mintzberg's [7] standardization of work processes, whereas common messages to customers and the definition of good service correspond to Mintzberg's [7] standardization of skills and norms. Lastly, ad hoc communication can be regarded as Mintzberg's [7] mutual adjustment. (See Fig. 2)

These results support the claim made by Thompson [6], according to which standardization is most efficient on the strategic level of the organization, whereas mutual adjustment is suitable on the operational level.

We state that in order to guarantee the quality of service offering and added value for the end customer, the organizations should organize their work as business processes crossing all the operations. We suggest that a common service process is a way of coordination that unites the strategic level and the operational level of the collaborative organizations (Fig. 2). The common service process also unites the different operations towards a shared business goal. However, the common service process 
should be managed by having a process owner that takes care of the development of the process [11].

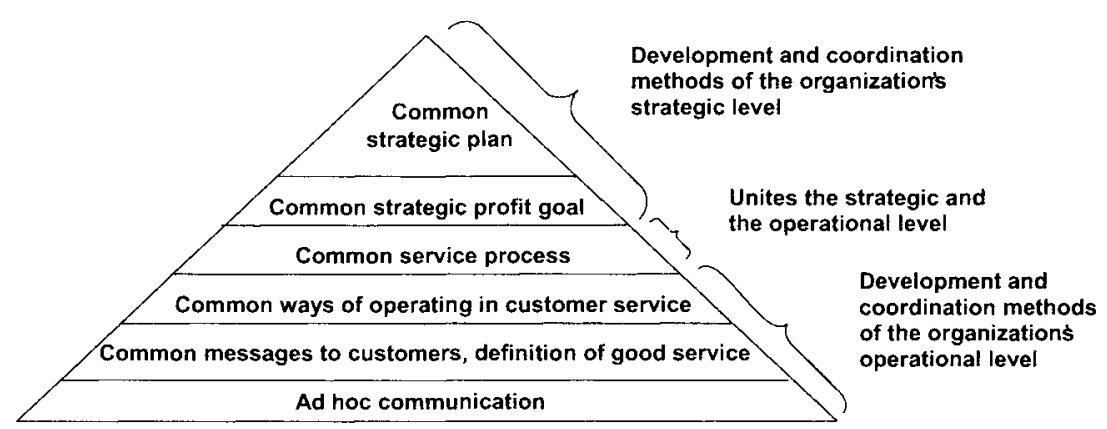

Fig. 2. Development and coordination methods of the collaborative organizations providing services to the common customers [3]

\section{Discussion and Evaluation}

The study implies that before starting to coordinate the operations of different organizations, cooperation between the organizations should be started and developed. This supports the statement made by Axelsson and Easton [10] according to which integration is needed before coordination can be performed.

The study confirms the known fact that personnel should be involved in the collaborative process early enough to get them committed to changes. It was important for the personnel of the case company that the managers made clear decisions about how to approach cooperation. The personnel needed to understand what kind of advantage could be gained from cooperation.

A message to managers is that successful integration of business units requires that the management is committed to the changes and encourages personnel to start using the ways of coordination agreed together. Our findings suggest that in the early phase of cooperation, the business units should define the common resources required for producing the products and services to common customers. In addition, communication between the business units should flow freely all the time in order to prevent misunderstandings between partners.

Lincoln and Guba [26] present four criteria of soundness of a qualitative study: credibility, transferability, dependability, and confirmability. The credibility of this study was increased by active collaboration between the management of the two business units and the researchers. In addition, triangulation, i.e., the use of different data collection methods, increased the credibility. The transferability of this study was increased by describing the case study in detail. The dependability is related to the objectivity and stability of the research. This criterion was met by describing the 
context in necessary detail. The confirmability was improved by describing the methods of research, data collection, and analysis in necessary detail.

This study is only a start in understanding how different business units within a company can be coordinated and integrated to serve common customers better. In consequence, the new framework should be developed further in new cases of collaborative service offering. It would be interesting to apply it in a different context, e.g., between business units from different companies.

\section{Acknowledgements}

This paper presents the central findings of Södergård's [3] Master's Thesis. The empirical data provides basis for an article in the final report of the Co-Create project that was published in SimLab's Report Series in June 2006.

The research reported in this paper has been conducted in Co-Create and Madeleine research projects at the Enterprise Simulation Laboratory SimLab, Department of Computer Science and Engineering, Helsinki University of Technology. The authors are grateful for the creative research effort of the whole research team which has made this paper possible. The research is financially supported by the following organizations which are gratefully acknowledged: Finnish Funding Agency for Technology and Innovation (Tekes) and partner companies.

\section{References}

1. C. Grönroos, Service Management and Marketing, in Finnish (WS Bookwell Oy, Porvoo, 2001).

2. T. W. Malone and K. Crowston, The Interdisciplinary Study of Coordination, ACM Computing Surveys. 26(1), 87-119 (1994).

3. R. Södergård, Developing Collaboration between Two Business Units: Integrating and Coordinating the Service Processes, in Finnish (Master's Thesis, Department of Computer Science and Engineering. Helsinki University of Technology, SimLab Report series 12, Espoo, 2005).

4. P. Lawrence and J. Lorsch, Organization and Environment (Harvard University Graduate School of Business Administration, Boston, 1986).

5. R. Hall, Organizations: Structures, Processes, and Outcomes (Prentice Hall, USA, 2002).

6. J. Thompson, Organizations in Action (McGraw-Hill, USA, 1967).

7. H. Mintzberg, The Structuring of Organizations (Prentice-Hall Englewood Cliffs, NJ, 1979)

8. G. Hoeg, Taken for Granted, Best's Review. 106(1), 101-102 (2005).

9. T. Simatupang, C. Wright and R. Sridharan, The Knowledge of Coordination for Supply Chain Integration, Business Process Management Journal. 8(3), 289-308 (2002).

10. B. Axelsson and G. Easton, Industrial Networks, a New View of Reality (Routledge, London, 1992).

11. J. Hannus, The Keys to Strategic Success. The Effective Strategies, Competences and Business Models, in Finnish (Gummerus, Jyväskylä, 2004). 
12. K. Mäkelä, Construction of Common Understanding. Interplay of Organizational Culture, Communication and Knowledge in Inter-company R\&D-projects, in Finnish (Master's thesis, Department of Communication, University of Helsinki, 2002).

13. M. Jaatinen and R. Lavikka, Common Understanding as a Basis for Coordination, Journal of Corporate Communications [to be published 2007].

14. H. Kvist, S. Arhomaa, K. Järvelin and J. Räikkönen, Customer processes. How to improve the return by developing processes, in Finnish (Gummerus Kirjapaino Oy, Jyväskylä, 1995).

15. L. Aberg, Communication management, in Finnish (Otavan Kirjapaino Oy, Keuruu, 2000)

16. B. Edvardsson and J. Olsson, Key Concepts for New Service Development, Service Industries Journal. 16(2), 140-164 (1996).

17. B. Danemark, M. Ekström, L. Jakobsen and Jan Ch. Karlsson, Explaining Society, Critical Realism in the Social Sciences (Routledge, London, UK, 1997).

18. M. Grönfors, Qualitative methods for fieldwork, in Finnish (WSOY, Juva, 1985).

19. K. Eisenhardt, Building Theories from Case Study Research, Academy of Management Review. 4(4), 532-551 (1989).

20. R. K. Yin, Case study research: design and methods (SAGE, Newbury Park, CA, 1989).

21. E. Gummesson, Qualitative Methods in Management Research (SAGE Publications, Thousand Oaks, California, 2000).

22. R. Smeds, P. Haho and J. Alvesalo, Bottom-up or top-down? Evolutionary change management in NPD processes, International Journal Technology Management. 26(8), 887902 (2003).

23. R. Smeds, M. Jaatinen, A. Hirvensalo and A. Kilpiö, SimLab process simulation method as a boundary object for inter-organizational innovation. (The 10th workshop of the IFIP WG 5.7 special interest group on experimental interactive learning in industrial management. Trondheim, Norway, June 11-13, 2006).

24. S. Hirsjärvi and H. Hurme, Theme interview - the theory and practice of theme interview, in Finnish (Yliopistopaino, Helsinki, 2004).

25. C. Marshall and G. Rossman, Designing Qualitative Research (SAGE Publications, Thousand Oaks, CA, 1995).

26. Y. Lincoln and E. Guba, Naturalistic inquiry (SAGE, Beverly Hills, CA, 1985). 